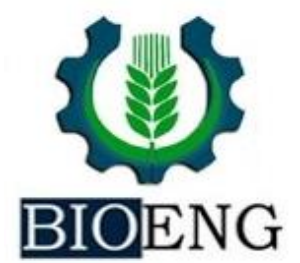

\title{
DIFERENTES DILUIÇÕES E USO DE RECICLO NA BIODIGESTÃO ANAERÓBIA DE CAMA DE FRANGO TRITURADA E PENEIRADA: ENSAIO BATELADA
}

${ }^{1}$ UNESP - Universidade Estadual Paulista, Faculdade de Ciências Agronômicas, Botucatu, SP, Brasil.

${ }^{2}$ UNIARA - Centro Universitário de Araraquara, Araraquara, SP, Brasil.

${ }^{3}$ UNESP - Universidade Estadual Paulista, Faculdade de Medicina Veterinária e Zootecnia, Jaboticabal, SP, Brasil.

Article history: Received 27 October 2017; Received in revised form 05 December 2017; Accepted 05 December 2017; Available online 27 December 2017.

\section{RESUMO}

A cama de frango gerada no processo produtivo das aves demonstra grande potencial para a obtenção de energia com o uso de biodigestores, porém é preciso que ela apresente algumas condições como separação de sólidos, para facilitar o processo. Objetivou-se neste trabalho avaliar a produção de biogás no processo de biodigestão anaeróbia da cama de frango com separação de sólidos, em diferentes diluições, com e sem utilização de $20 \%$ de reciclo (biofertilizante) em sistema batelada de abastecimento. Foram utilizados 24 biodigestores batelada, com capacidade de $2 \mathrm{~L}$ de substrato em fermentação. $\mathrm{O}$ equipamento utilizado para processamento da cama de frango foi uma bomba trituradora que homogeneíza e tritura a cama em partículas menores para facilitar e melhorar a eficiência na biodigestão. Para a separação da fração sólida foi utilizada uma peneira vibratória com malha de $1 \mathrm{~mm}$. Foram estudadas as diluições 1:8, 1:10 e 1:12 e $20 \%$ de reciclo em substituição a água. O tratamento cama de frango na diluição 1:8 foi o que apresentou maior redução de sólidos voláteis $(72,76 \%)$ em relação aos outros tratamentos. O tratamento com reciclo na diluição 1:8 foi o que apresentou maior produção de biogás com valor médio de $0,0328 \mathrm{~m}^{3}$, em relação aos demais tratamentos. Conclui-se que a utilização do reciclo não interfere e provoca aumento na produção de biogás.

Palavras-chave: Avicultura, biodigestor batelada e biogás

\section{DIFFERENT DILUTIONS AND USE OF RECYCLE IN THE ANAEROBIC BIODIGESTION OF CRUSHED AND SIEVED POULTRY LITTER: BATCH TEST.}

\begin{abstract}
The poultry litter generated in the production process bird shows great potential for obtaining energy using biodigesters, but it is necessary and it is able to facilitate the process and separation of solids. The objective of the work was to produce biogas in the process of biodigestion, with different solutions, with a $20 \%$ use of recycle in a batch supply system. Twenty-four batch digesters were used, with a capacity of $2 \mathrm{~L}$ of substrate in fermentation. The equipment used for processing the chicken litter was a crusher pump that homogenizes and crushes the chicken litter into smaller particles to facilitate and improve efficiency in biodigestion. For a separation of the solid fraction for a $1 \mathrm{~mm}$ mesh vibrating screen. Dilutions 1: $8,1: 10$ and 1:12 and 20\% recycle (biofertilizer) were studied in substitution of water. The
\end{abstract}


treatment of poultry litter in a dilution of 1: 8 showed the greatest reduction in volatile solids (72.76\%) compared to other treatments. The treatment with recycle at the 1: 8 dilution was the one with the highest biogas production with an average value of $0.0328 \mathrm{~m}^{3}$, in relation to the other treatments. It is concluded that the use of the recycle does not interfere in the production of biogas and there was an increase in the production.

Keywords: Poultry, Batch biodigestor and biogas.

\section{INTRODUÇÃO}

A crise energética e os problemas ambientais decorrentes a partir da utilização de fontes poluentes e não renováveis de energia mudaram o cenário mundial sobre este tema, levando para a busca de soluções sustentáveis nos três âmbitos: econômico, ambiental e social, no Brasil, a utilização da biomassa como fonte de energia vem aumentando ano após ano (OLIVEIRA et al., 2011).

A avicultura de corte origina uma vasta quantidade de resíduos (cama de frangos) que, se bem manejados, poderão ser uma importante fonte de renda $\mathrm{e}$ cooptação de valor à atividade, também um exemplo de produção sustentável que vem sendo cada vez mais uma cobrança de mercado. Por tanto, é imprescindível que tenha a adoção de um sistema de tratamento como a biodigestão anaeróbia, a fim de evitar possíveis contaminações do ambiente (SARMENTO et al., 2015).

A biodigestão anaeróbia é uma tecnologia comprovada de gerenciamento de resíduos que mitiga as emissões de odor, patógenos e gases de efeito estufa. Além disso, a produção de biogás as como energia renovável e o biofertilizante rico em nutrientes (ZEB et al., 2017).

O biogás é geralmente composto de 48-65\% de metano, $36-41 \%$ de dióxido de carbono, até $17 \%$ de nitrogênio, $<1 \%$ de oxigênio, 32-169 ppm de sulfato de hidrogênio e vestígios de outros gases. Ao contrário do combustível fóssil, o biogás não contribui muito para o efeito de estufa, o esgotamento do ozônio ou a chuva ácida (KHALID et al., 2011). Sendo esta uma das principais razões pelas quais a digestão anaeróbia pode desempenhar um papel muito importante no enfrentamento dos desafios energéticos da geração futura.
O uso de biodigestores na produção animal é visto como uma importante ferramenta, pois, além de promover o tratamento dos resíduos, retorna ao sistema produtivo parte da energia que seria perdida, por meio do biogás (SILVA et al., 2005; ORRICO et al., 2007; SANTOS et al., 2007; FARIAS et al.,2012).

$\mathrm{O}$ biodigestor batelada opera de forma descontinua, ou seja, é alimentado de uma só vez, com uma grande quantidade de matéria orgânica e, depois são fechados para não permitir a entrada de oxigênio. $O$ tempo de retenção hidráulica pode variar de 30 a 60 dias ou até a produção de biogás comece a cair, indicando que toda matéria orgânica já foi decomposta.

A cama de frango necessita de um pré-tratamento antes de ser abastecida no biodigestor. A trituração ou moagem é uma forma de tornar o material com granulometria adequada, para não inibir as atividades dos microrganismos, (AIRES, 2009). Outro procedimento de prétratamento é o peneiramento em malha para retirar parte do material de difícil degradação.

Para que a cama de frango torne-se um material apropriado para ser abastecido em biodigestor, deve ser diluída em água no primeiro momento e após alguns dias de operação do biodigestor, pode-se reutilizar o biofertilizante em novo processo de abastecimento diluindo cama de frango o que se pode denominar reciclo.

Objetivou-se, estudar três diluições, com menor, media e maior quantidade de sólidos totais e a inclusão de $20 \%$ de reciclo (biofertilizante) em substituição a água de diluição da cama de frango, para avaliar a produção de biogás. 


\section{MATERIAL E MÉTODOS}

\section{Local e descrição do experimento}

A pesquisa foi realizada no Laboratório de Biodigestão Anaeróbia do Departamento de Engenharia Rural da Faculdade de Ciências Agrárias e Veterinárias/UNESP- Campus de Jaboticabal.

Para o experimento foram utilizados 24 biodigestores tipo batelada, os quais possuem capacidade útil de dois litros de substrato em fermentação e os biodigestores foram instalados no interior do laboratório. A figura 1 representa o modelo de biodigestor.
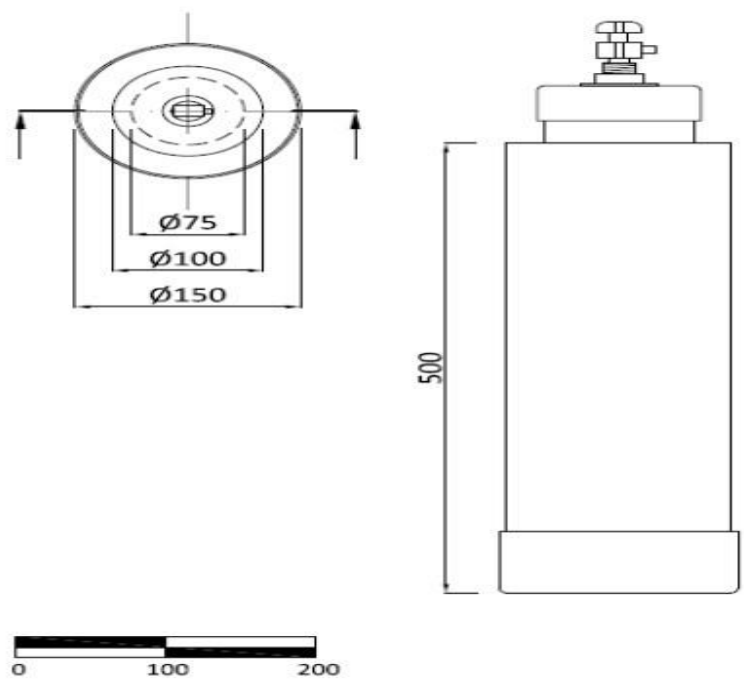

Figura 1. Vista superior, vista frontal e corte de um biodigestor tipo batelada, medidas em mm. Fonte: SANTI, 2013

\section{Cálculo da diluição}

Para calcular a diluição determinouse um volume de substrato a ser preparado e também a diluição na forma de proporção (fator diluição). A quantidade de cama de frango foi determinada pela seguinte formula: volume total do substrato $\mathrm{X}$ fator diluição. Obtendo-se a quantidade de cama de frango que era subtraída do valor total de substrato, obtendo-se a quantidade de água a ser utilizada para diluir a cama de
A cama de frango utilizada no experimento é de quarta reutilização composta por casca de amendoim, proveniente de galpão convencional localizado no município de Monte Alto SP. O teor de sólido total da cama de frango foi de $88 \%$ e sólido volátil de $77 \%$.

Para a execução do ensaio, foi utilizado delineamento inteiramente casualizado no esquema fatorial duplo $3 \times 2$, sendo constituído por três diluições (1:8, $1: 10$ e $1: 12$ ) e com e sem $20 \%$ de reciclo, com separação de sólidos e cada tratamento contou com 4 repetições. O experimento foi conduzido com um tempo de retenção hidráulica de 196 dias.

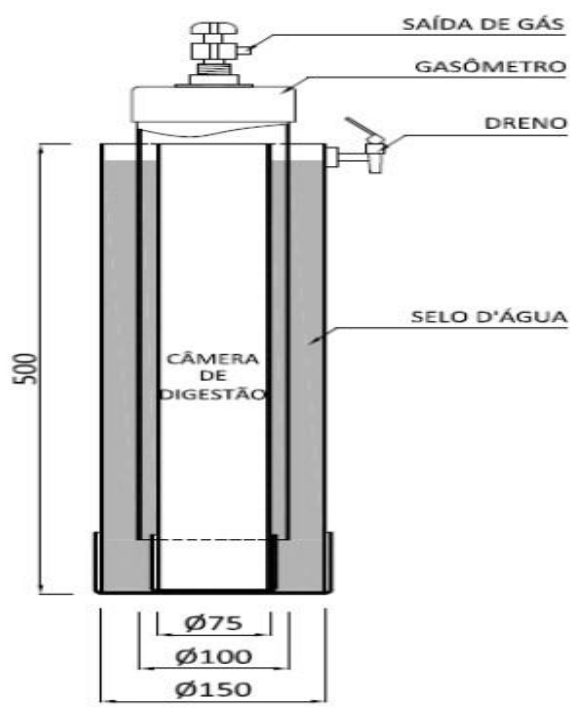

frango. A quantidade de reciclo era obtida sobre o valor da água de acordo com a porcentagem estabelecida.

\section{Reciclo}

O reciclo utilizado no experimento, foi feito com a mesma cama de frango, com preparo de 40 dias antes, para o abastecimento dos biodigestores batelada. Foi preparado de acordo com as diluições $1: 8,1: 10$ e $1: 12$. 
Preparo do substrato e abastecimento dos biodigestores

Para o preparo do substrato utilizouse uma bomba trituradora da marca Homa, para promover trituração e mistura homogênea do substrato, e em seguida determinou-se uma quantidade de $100 \mathrm{~kg}$ de substrato a ser preparada, para as seguintes proporções de diluição $(1: 8,1: 10$ e 1:12). Sendo as quantidades de cama de frango, água e reciclo, estão descritos na Tabela 1 e 2 .
Em um tambor colocava-se a cama de frango, água e reciclo, de acordo com cada tratamento, deixava-se a bomba misturar o substrato por cinco minutos e depois era bombeado o substrato para fazer a separação da fração sólida, utilizando-se uma peneira vibratória com malha de diâmetro de um mm. Este procedimento foi feito para as três diluições estudadas (1:8, $1: 10$ e $1: 12$ ).

Tabela 1. Quantidade $(\mathrm{kg})$ de cama de frango, água e reciclo.

\begin{tabular}{llll}
\hline Diluição & Cama de Frango & Água & Reciclo \\
\hline $\mathbf{1 : 8}$ & 12,5 & 70 & 17,5 \\
\hline $\mathbf{1 : 1 0}$ & 10 & 72 & 18 \\
\hline $\mathbf{1 : 1 2}$ & 8,35 & 73,32 & 18,33 \\
\hline
\end{tabular}

Tabela 2. Quantidade (kg) de Cama de Frango e água.

\begin{tabular}{lll}
\hline Diluição & Cama de Frango & Água \\
\hline $\mathbf{1 : 8}$ & 12,5 & 87,5 \\
\hline $\mathbf{1 : 1 0}$ & 10 & 90 \\
\hline $\mathbf{1 : 1 2}$ & 8,35 & 91,65 \\
\hline
\end{tabular}

Foram abastecidos 24 biodigestores, com $1,9 \mathrm{~kg}$ de um substrato nas seguintes condições:

Cama de frango + água na diluição 1:8 (CF 1:8);

Cama de frango + água + 20\% de reciclo na diluição 1:8 (CFR 1:8);

Cama de frango + água na diluição 1:10 (CF 1:10);

Cama de frango + água + 20\% de reciclo na diluição 1:10 (CFR 1:10);

Cama de frango + água na diluição 1:12 (CF 1:12;

Cama de frango + água $+20 \%$ de reciclo na diluição 1:12 (CFR 1:12).

\section{Análises laboratoriais}

\section{Teores de sólidos totais e voláteis}

Para determinação de sólidos totais, as amostras dos afluentes e efluentes dos biodigestores foram acondicionadas em triplicata em recipientes de alumínio, previamente tarados, pesados para obtenção do peso úmido $(\mathrm{Pu})$ do material. Após a pesagem, foram levados à estufa com circulação forçada de ar, à temperatura de $65^{\circ} \mathrm{C}$, até atingirem peso constante, sendo a seguir resfriadas em dessecador e novamente pesadas em balança com precisão de $0,01 \mathrm{~g}$, obtendo-se então o peso seco (Ps). O teor de sólidos totais foi determinado de acordo metodologia descrita por APHA (2005).

Para a determinação dos sólidos voláteis, o material já seco em estufa, resultante da determinação dos sólidos totais, foi levado à mufla, em cadinhos de porcelana previamente tarados e mantidos a uma temperatura de $575^{\circ} \mathrm{C}$ por um período de 2 horas e 30 minutos. Após o término da queima, os cadinhos foram 
retirados da mufla e levados ao resfriamento em dessecadores. O material resultante foi pesado em balança analítica com precisão de $0,0001 \mathrm{~g}$, obtendo-se o

\section{Cálculo da produção de biogás}

Para a produção de biogás foi realizada leitura conforme o acúmulo no gasômetro. A leitura consistiu, na medição da altura aferida em régua fixada junto ao gasômetro, que se deslocava verticalmente. $\mathrm{O}$ número obtido na leitura foi multiplicado pela área de seção transversal interna dos gasômetros, igual a 0,00785 $\mathrm{m}^{2}$. Após cada leitura os gasômetros foram zerados utilizando-se o registro de descarga do biogás. A correção do volume de biogás para as condições de $1 \mathrm{~atm}$. em $20^{\circ} \mathrm{C}$, foi efetuada com base no trabalho de CAETANO (1985), onde pelo fator de compressibilidade $(\mathrm{Z})$, o biogás apresenta comportamento próximo ao ideal.

Para a correção do volume de biogás, utiliza-se a expressão resultante da combinação das leis de Boyle e GayLussac, na Equação (1) onde:

$\frac{\mathrm{V} 0 \mathrm{xP} 0}{\mathrm{~T} 0}=\frac{\mathrm{V} 1 \mathrm{xP} 1}{\mathrm{~T} 1}$

Eq.1

em que:

$\mathrm{V}_{0}=$ volume de biogás corrigido, $\mathrm{m}^{3}$;

$\mathrm{P}_{0}=$ pressão corrigida do biogás, $10.33 \mathrm{~mm}$ de $\mathrm{H}_{2} \mathrm{O}$;

$\mathrm{T}_{0}=$ temperatura corrigida do biogás, 293,15 K;

$\mathrm{V}_{1}=$ volume do gás no gasômetro; peso das cinzas ou matéria mineral. Os teores de sólidos voláteis foram determinados segundo a metodologia descrita por APHA (2005).

$\mathrm{P}_{1}=$ pressão do biogás no instante da leitura, 9673,24 mm de $\mathrm{H}_{2} \mathrm{O}$;

$\mathrm{T}_{1}=$ temperatura do biogás, em $\mathrm{K}$, no instante da leitura.

Considerando-se a pressão atmosférica média de Jaboticabal igual a 9627,24 mm de água e pressão conferida pelos gasômetros de $46 \mathrm{~mm}$ de água, obtém-se como resultado Equação (2) a seguinte expressão, para correção do volume de biogás:

$\mathrm{V}_{0}=\mathrm{V}_{1} / \mathrm{T}_{1} * 274,70$

Eq.2

\section{Teste de queima}

Este teste consistiu na verificação de queima ou não do biogás proveniente dos biodigestores em batelada para detecção de presença ou não de metano em quantidade suficiente para manter uma chama. $O$ teste era realizado com um Bico de Bunsen, cuja mangueira era acoplada à saída de gás do gasômetro. Em presença de chama continua (Figura 2) confirmava-se a queima, o que significa que há uma quantidade de metano, que representa cerca de $50 \%$ do volume, o que também é sinal de que a flora microbiana se desenvolveu nas proporções certas para que o processo anaeróbio aconteça da forma desejada e assim iniciando $o$ abastecimento diário.

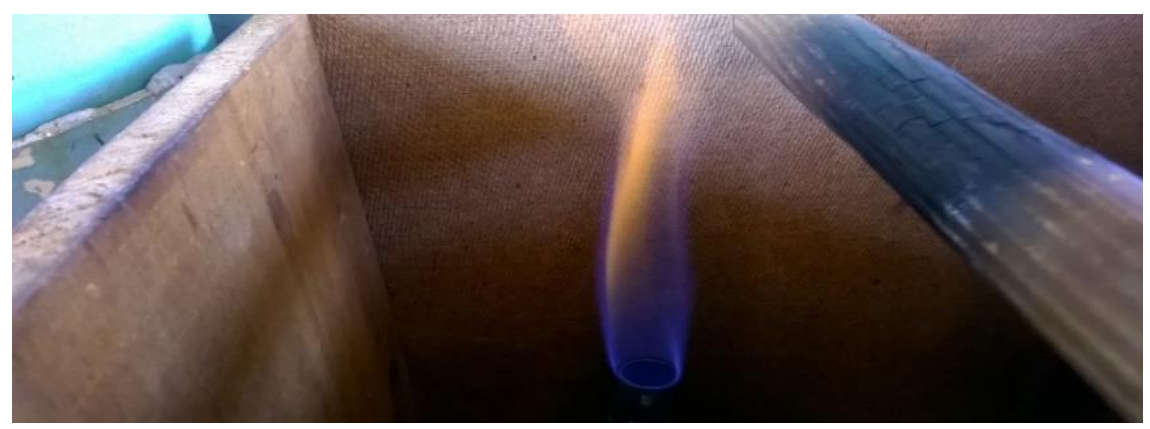

Figura 2. Demonstração da queima do biogás, feita pelo teste de queima.

Fonte: Própria 
Análise dos dados

Os dados obtidos para redução de sólidos voláteis, produção de biogás em $\mathrm{m}^{3}$, potenciais de $\mathrm{m}^{3}$ de biogás por $\mathrm{kg}$ de cama de frango, substrato, de ST

\section{RESULTADOS E DISCUSSÃO}

\section{Teores de sólidos totais e voláteis}

Os teores médios de sólidos totais (ST) e sólidos voláteis (SV), em porcentagem e em massa, dos substratos estão representados na tabela 3. Os resultados se referem aos dejetos que foram utilizados no abastecimento dos biodigestores (afluente) e ao adicionados, de SV adicionados foram submetidos à análise de variância pelo procedimento GLM do SAS program version 9.1 (2003) e as médias comparadas pelo teste de Tukey a um nível de significância de $5 \%$.

biofertilizante, obtido após o processo (efluente).

Observando-se, na tabela 3, notam-se que os valores dos teores de sólidos totais do abastecimento (afluente) para os três tipos de diluição estão apropriados para o processo de biodigestão anaeróbia, pois Seadi (2008) descreve que o teor de sólidos totais deve estar entre $4-8 \%$.

Tabela 3. Valores de sólidos totais e voláteis em massa e em porcentagem.

\begin{tabular}{ccccccccc}
\hline \multirow{2}{*}{ Tratamento } & \multicolumn{2}{c}{ Solidos totais (\%) } & \multicolumn{2}{c}{ Sólidos totais $(\mathrm{kg})$} & \multicolumn{2}{c}{ Solidos volateis $(\%)$} & \multicolumn{2}{c}{ Sólidos Volateis $(\mathrm{Kg})$} \\
\cline { 2 - 9 } & Afluente & Efluente & Afluente & Efluente & Afluente & Efluente & Afluente & Efluente \\
\hline CF1:8 & 8,02 & 2,86 & 0,1524 & 0,0544 & 6,21 & 1,69 & 0,1181 & 0,0322 \\
CFR1:8 & 8,85 & 3,95 & 0,1681 & 0,0750 & 6,59 & 2,18 & 0,1253 & 0,0414 \\
CF1:10 & 7,24 & 3,06 & 0,1376 & 0,0581 & 5,52 & 1,89 & 0,1048 & 0,0358 \\
CFR1:10 & 6,37 & 3,58 & 0,1210 & 0,0680 & 4,77 & 2,14 & 0,0906 & 0,0407 \\
CF1:12 & 5,25 & 2,47 & 0,0997 & 0,0469 & 4,09 & 1,46 & 0,0777 & 0,0277 \\
CFR1:12 & 5,87 & 2,93 & 0,1116 & 0,0556 & 4,44 & 1,68 & 0,0844 & 0,0320 \\
\hline
\end{tabular}

Não foram observadas interações significativas $(\mathrm{P}>0,05)$ entre reciclo e a diluição nas reduções de sólidos voláteis (Tabela 4). Os valores médios de reduções de sólidos voláteis para os três tipos de diluição foram de $67 \%$ sem reciclo e $61 \%$ com reciclo, caracterizando que uso do biodigestor foi eficiente para as reduções de sólidos voláteis, devido a cama de frango ser material de difícil degradação.
Orrico Jr., Orrico e Lucas Jr. (2010) obtiveram valores de reduções de sólidos voláteis de $44 \%$ em biodigestores abastecidos com os resíduos de aves mortas e cama de frangos pré-compostados e Aires et al. (2009) apresentaram valores de reduções de $65 \%$ no processo de biodigestão de cama de frango com separação de sólidos, valores semelhantes aos encontrados neste trabalho. 
Tabela 4. Reduções sólidas voláteis para três diluições e com e sem reciclo.

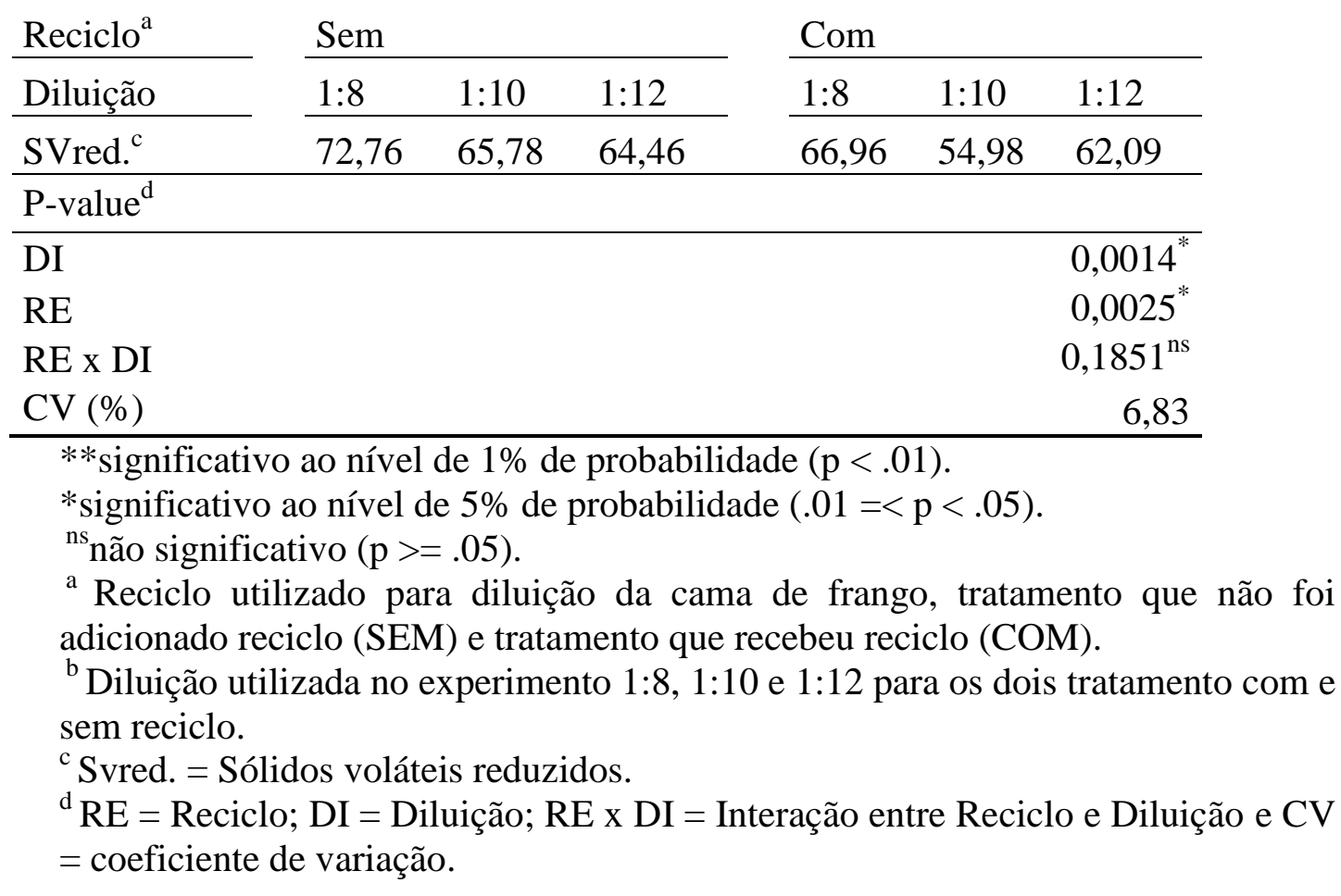

Costa (2009) em seu experimento utilizando cama de frango diluída com biofertilizante de suínos em biodigestores batelada, apresentou resultados de reduções de sólidos voláteis de 60,99 e 67,20\% para os tratamentos com cama de frango + biofertilizante e cama de frango + água respectivamente, semelhante ao encontrado neste trabalho.

A redução de sólidos voláteis, demostra a eficiência quanto a matéria orgânica ou substrato são convertidos em biogás assim degradando material. Segundo Santos (2001) a maior redução de sólidos nos substratos preparados com camas reutilizadas se deve a maior quantidade de excretas (maior acumulo devido à criação de dois lotes de aves na mesma cama), em relação ao material utilizado como cama, o que no caso seria a maravalha e Lucas Jr., (1994), relata que quanto maior for a concentração de sólidos voláteis, dentro de certos limites, na alimentação diária do biodigestor $\left(\mathrm{kg} / \mathrm{m}^{3}\right)$, maior será a capacidade de produção de biogás

\section{Potenciais de produção de biogás}

Para os potenciais de produção de biogás, foram observadas interações significativas entre sólidos totais adicionados $(\mathrm{p}<0,01), \quad$ voláteis adicionados ( $\mathrm{p}<0,01)$, cama de frango ( $\mathrm{p}$ $<0,0231)$ e substrato $(\mathrm{p}<0,0234)$ (Tabela $5)$.

A produção média de biogás por $\mathrm{kg}$ de sólidos totais adicionados (STadic.) o que apresentou melhor resultado foi $\mathrm{o}$ tratamento com diluição $1: 12$ + reciclo, não diferenciando do tratamento com diluição 1:12 + água. Em relação aos sólidos voláteis adicionados (SVadic.), o tratamento com diluição 1:12 com e sem reciclo foi o que apresentaram melhores produção de biogás por $\mathrm{kg}$ de SVadic.

Costa (2012) obteve resultados de produção de biogás por $\mathrm{kg}$ de STadic. quando efetuou a biodigestão anaeróbia de cama de frango de terceiro lote com biofertilizante com separação de sólidos a 3 e $6 \%$, com média de produção de biogás por STadic. de 0,2815 com sólidos totais de $3 \%$ e de 0,6035 para $6 \%$ ST. Sendo o resultado de $3 \%$ de sólidos totais semelhante ao encontrado nesta pesquisa e com $6 \%$ foi superior. 
Tabela 5. Potenciais de produção de biogás, expressos em $\mathrm{m}^{3}$ de biogás por $\mathrm{kg}$ de sólidos totais adicionados (STadic.) e sólidos voláteis adicionados (SVadic.) e por kg cama de frango e substrato.

\begin{tabular}{|c|c|c|c|c|c|c|c|c|c|c|}
\hline Reciclo $^{a}$ & & Sem & & & Com & & & P-value & & \\
\hline Diluição $^{b}$ & $1: 8$ & 1:10 & 1:12 & $1: 8$ & 1:10 & 1:12 & DI & $\mathrm{RE}$ & RE $x$ DI & $\mathrm{CV}(\%)$ \\
\hline Solidos totais adicionados & $0,1432 \mathrm{e}$ & $0,2022 \mathrm{dc}$ & $0,2455 \mathrm{ab}$ & $0,1953 d$ & $0,2263 b c$ & $0,2578 \mathrm{a}$ & $0,0001 * *$ & $0,0001 * *$ & $0,0001 * *$ & 6,06 \\
\hline Solidos volateis adicionado & $0,1849 d$ & $0,2653 b c$ & $0,3151 \mathrm{a}$ & $0,2620 \mathrm{c}$ & $0,3023 \mathrm{ab}$ & $0,3409 \mathrm{a}$ & $0,5760^{\mathrm{ns}}$ & $0,0001 * *$ & $0,0001 * *$ & 6,69 \\
\hline Cama de frango & $0,0921 \mathrm{c}$ & $0,1464 b$ & $0,1542 b$ & $0,1381 b$ & $0,1441 b$ & $0,1813 \mathrm{a}$ & $0,0001^{* *}$ & $0,0001 * *$ & $0,0231^{*}$ & 6,29 \\
\hline Substrato & $0,0115 \mathrm{~d}$ & $0,0146 b c$ & $0,0129 \mathrm{dc}$ & $0,0172 \mathrm{a}$ & $0,0144 b c$ & 0,0151ab & $0,0001 * *$ & $0,0001 * *$ & $0,0234^{*}$ & 6,33 \\
\hline
\end{tabular}

As médias seguidas pela mesma letra não diferem estatisticamente entre si $(\mathrm{p}<0.05)$.

** Significativo ao nível de $1 \%$ de probabilidade $(\mathrm{p}<.01)$.

* Significativo ao nível de $5 \%$ de probabilidade $(.01=<\mathrm{p}<.05)$.

${ }^{\mathrm{ns}}$ não significativo $(\mathrm{p}>=.05)$.

${ }^{\text {a }}$ Reciclo utilizado para diluição da cama de frango, tratamento que não foi adicionado reciclo (SEM) e tratamento que recebeu reciclo (COM).

${ }^{\mathrm{b}}$ Diluição utilizada no experimento 1:8, 1:10 e 1:12 para os dois tratamento com e sem reciclo.

${ }^{c}$ RE = Reciclo; DI = Diluição; RE x DI = Interação entre Reciclo e Diluição e CV = coeficiente de variação.

Tessaro (2015) apresentou em seu experimento valores médios de $(0,4106 \pm 0,0128), \quad(0,3264 \pm 0,0243) \quad$ e $(0,0804 \pm 0,0023) \mathrm{m}^{3}$ biogás por $\mathrm{kg} \mathrm{de}$ substrato no processo de biodigestão anaeróbia com os tratamentos com cama de frango + biofertilizante + água, cama de frango + biofertilizante e cama de frango + água respectivamente e Silveira (2014) obteve valores de 0,023, 0,027 e 0,032 $\mathrm{m}^{3} * \mathrm{~kg}^{-1}$ de biomassa para cama de frango com água em três diferentes porcentagens de água, pode-se observar que a produção de biogás com a cama de frango tem vários fatores que interferem em uma maior ou menor produção de biogás, um fator importante é quantas vezes a cama de frango foi reutilizada, quanto maior a reutilização, maior $\mathrm{o}$ teor de matéria orgânica em sua composição.

\section{Produção de biogás}

A figura 3 representa graficamente a produção total de biogás do período de 196 dias, nota-se que os tratamentos com reciclo independentemente da diluição foram os que apresentaram maior produção de biogás.

Pode-se observar que a maioria dos tratamentos obteve um pico de produção de biogás aos 35 dias, com exceção do tratamento $\mathrm{CF} 1: 10$ que demostrou um pico de produção aos 70 dias e também o tratamento CFR1:10 apresenta uma queda acentuada de produção de biogás aos 63 dias.

Os tratamentos com reciclo CFR 1:8 e 1:12 apresentaram semelhança na produção de biogás, porém o tratamento CFR 1:8 aos 140 dias produziu um pequeno pico de produção de biogás, enquanto aos demais tratamentos já não estavam produzindo biogás. 


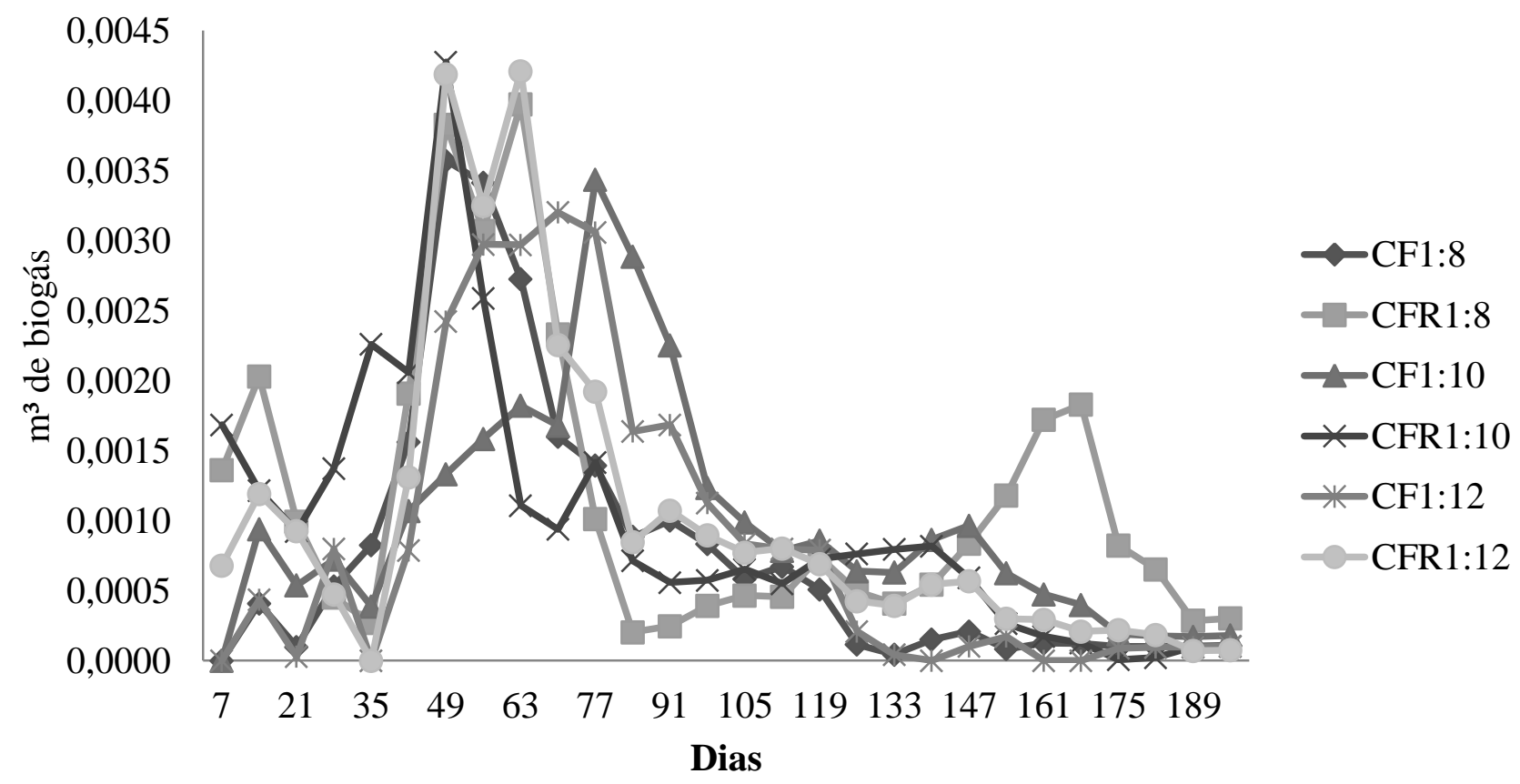

Figura 3. Distribuição da produção do biogás (m3) em 7 dias.

Pode-se observar que o comportamento da curva de produção de biogás na Figura 3 foi aparentemente igual para todos os tratamentos. Este comportamento da curva de produção pode estar relacionado ao fato da cama de frango ser uma mistura de componentes heterogêneos, agrupando substâncias de rápida degradação (amido e carboidratos), que são responsáveis pela rápida liberação de gás carbônico e substâncias de degradação lenta, como o caso da lignina, celulose e hemicelulose.

A produção média de biogás total, em $\mathrm{m}^{3}$, está representada na Tabela 6 , o tratamento com diluição 1:8 mais reciclo foi com valor médio de produção de biogás de $0,0328 \mathrm{~m}^{3}$, foi que apresentou maior produção de biogás.

Tabela 6. Produção de biogás $\left(\mathrm{m}^{3}\right)$.

\begin{tabular}{|c|c|c|c|c|c|c|}
\hline Reciclo $^{\mathrm{a}}$ & \multicolumn{3}{|c|}{ Sem } & \multicolumn{3}{|c|}{ Com } \\
\hline Diluição $^{\text {b }}$ & $1: 8$ & $1: 10$ & $1: 12$ & 1:8 & $1: 10$ & $1: 12$ \\
\hline Prod.biogás & $0,0219 \mathrm{~d}$ & $0,0278 b c$ & $0,0245 \mathrm{~cd}$ & $0,0328 \mathrm{a}$ & $0,0273 b c$ & $0,0287 b$ \\
\hline \multicolumn{7}{|l|}{ P-value ${ }^{c}$} \\
\hline DI & & & & & & $0,5362^{\mathrm{ns}}$ \\
\hline RE & & & & & & $0,0001 * *$ \\
\hline RE x DI & & & & & & $0,0040 * *$ \\
\hline CV (\%) & & & & & & 6,58 \\
\hline
\end{tabular}

As médias seguidas pela mesma letra não diferem estatisticamente entre si $(\mathrm{p}<0.05)$.

$* *$ Significativo ao nível de $1 \%$ de probabilidade $(\mathrm{p}<.01)$.

* Significativo ao nível de $5 \%$ de probabilidade $(.01=<\mathrm{p}<.05)$.

${ }^{\mathrm{ns}}$ não significativo $(\mathrm{p}>=.05)$.

a Reciclo utilizado para diluição da cama de frango, tratamento que não foi adicionado reciclo (SEM) e tratamento que recebeu reciclo (COM).

${ }^{\mathrm{b}}$ Diluição utilizada no experimento 1:8, 1:10 e 1:12 para os dois tratamento com e sem reciclo. 
${ }^{\mathrm{c}} \mathrm{RE}=$ Reciclo; DI = Diluição; RE x DI = Interação entre Reciclo e Diluição e CV = coeficiente de variação.

Os tratamentos com diluição de cama de frango com $20 \%$ de reciclo apresentaram bons resultados de produçao de biogás, indicando que pode substituir água por reciclo e gerar biogás.

Suzuki et al. (2012) em seu experimento com cama de frango peneirada e diluida em água residuária de indústria de fécula de mandioca obteve produçao de biogas bem inferiores ao encontado neste experimento.

\section{CONCLUSÃO}

A utilização do reciclo proporcionou um aumento na produção de biogás, sendo indicado o uso do reciclo para a diluição da cama de frango, além de evitar o gasto de água potavel, constituíndo-se em alternativa para o avicultores aumentarem a geração de energia com este procedimento e com isso evitando problema com energia além de muitos
Costa (2012) encontrou valores de $0,7736 \mathrm{~m}^{3}$ de biogás em cama de frango + água com diferentes proporções de sólidos totais e valores de $0,7500 \mathrm{~m}^{3}$ de biogás em cama de frango + biofertilizante, ambos com cama de frango de $3^{\circ}$ lote de reutilização, valores maiores aos encontrados nesse trabalho.

utilizarem o biogás para o aquecimento dos pitinho quando alojados no primeiros dias, tornando mais economia com gasto de lenha ou com gás.

As diluições da cama de frangos nas proporções 1:8 e 1:12 com parte da água sendo substituída pelo reciclo apresentaram melhores resultados para a produção de biogás.

\section{AGRADECIMENTO}

Ao CNPq pela concessão da bolsa de estudos.

\section{REFERÊNCIAS}

AIRES, A. M.; LUCAS JR, J.; FUKAYAMA, E. H.; ROMANTINE, C. M.; GUIDOLIN, D. G. F. Biodigestão anaeróbia da cama de frangos de corte com ou sem separação das frações sólida e líquida sobre a produção de biogás e a qualidade do biofertilizante. In: AUGM Congresso de Meio Ambiente da Associação de Universidades Grupo de Montevidéu, 2009, São Carlos-SP. Anais de Eventos da UFSCar, 2009. v. 6. p. 1-15.

\footnotetext{
AIRES, A. M. Biodigestão anaeróbia da cama de frango com ou sem separação das frações sólida e líquida. 2009. $134 \mathrm{f}$. Dissertação (Mestrado em Produção Animal)-Faculdade de Ciências Agrárias e Veterinárias, Universidade Estadual Paulista, Jaboticabal, 2009.
}

\begin{abstract}
AMERICAN PUBLIC HEALTH ASSOCIATION. Standart methods for the examination of water andwastewater.20th ed. Washington, DC, 2005.
\end{abstract}

CAETANO, L. Proposição de um sistema modificado para quantificação de biogás. 1985. 75f. Dissertação (Mestrado em Energia na Agricultura)-Faculdade de Ciências Agronômicas, Universidade Estadual Paulista, Botucatu, 1985.

COSTA, L. V. C. Produção de biogás utilizando cama de frango diluída em água e em biofertilizante de dejetos de suínos. 2012. 75 f. Tese (Doutorado em Energia na agricultura)-Faculdade de 
Ciências Agronômicas, Universidade Estadual Paulista, Botucatu, 2012.

FARIAS, Romildo Marques de et al. Biodigestão anaeróbia de dejetos de poedeiras coletados após diferentes períodos de acúmulo. Ciência Rural, [s.l.], v. 42, n. 6, p.1089-1094, jun. 2012. Fap UNIFESP (SciELO).

http://dx.doi.org/10.1590/s0103-

84782012005000031 .

KHALID, Azeem et al. The anaerobic digestion of solid organic waste. Waste Management, [s.1.], v. 31, n. 8, p.17371744, ago. 2011. Elsevier BV. http://dx.doi.org/10.1016/j.wasman.2011.0 3.021 .

LUCAS JÚNIOR, J. Algumas considerações sobre o uso do estrume de suínos como substrato para três sistemas de biodigestores anaeróbios. 1994. $137 \mathrm{f}$. Tese (Livre- Docência Construções Rurais) - Faculdade de Ciências Agrárias e Veterinárias, Universidade Estadual Paulista, Jaboticabal, 1994.

OLIVEIRA, S. V. W. B.; LEONETI, A.V.; CALDO G. M. M.; DE OLIVEIRA, M. M. B.; Generation of bioenergy and biofertilizer on a sustainable rural property Biomass and Bioenergy, Volume 35, Issue 7, Julho 2011, p. 2608-2618

ORRICO, A.C.A. et al. Caracterização e biodigestão anaeróbia dos dejetos de caprinos. Engenharia Agrícola, v.27, n.3, p.639-647, 2007.

ORRICO JÚNIOR, M.A.P.; LUCAS JÚNIOR, J.; BIODIGESTÃO ANAERÓBIA DOS RESÍDUOS DA PRODUÇÃO AVÍCOLA: CAMA DE FRANGOS E CARCAÇAS. Engenharia Agrícola, Jaboticabal, v.30, n.3, p.546554, maio/jun. 2010.

SAS INSTITUTE. SAS version 9.1. Cary: SAS Institute, 2003.
SARMENTO, Zito Rigo Sarmento et al. APROVEITAMENTO DO POTENCIAL ENERGÉTICO DA CAMA DE FRANGO PARA USO NA ATIVIDADE AVÍCOLA. In: XI CONGRESSO NACIONAL DE EXCELÊNCIA EM GESTÃO, Não use números Romanos ou letras, use somente números Arábicos., 2015, Rio de Janeiro. Anais... . Rio de Janeiro: Cneg \& Inovarse, 2015. p. 1 - 15.

SANTOS,T. M. B. Balanço energético e adequação do uso de biodigestores em galpões de frango de corte. 2001. $167 \mathrm{f}$. Tese (Doutorado em Produção Animal) Faculdade de Ciências Agrárias e Veterinárias, Universidade estadual Paulista, Jaboticabal, 2001.

SANTOS, T.M.B. et al. Avaliação do desempenho de um aquecedor para aves adaptado para utilizar biogás como combustível. Engenharia Agrícola, v.27, n.3, p. 658-664, 2007.

SANTI, Lorenzo. Influência da adição de enzimas e microrganismos sobre a digestão anaeróbia de dejetos bovinos e suínos. 2013. 57 f. Dissertação (Mestrado) - Curso de Zootecnia, Universidade Estadual Paulista, Faculdade de Ciências Agrárias e Veterinárias, Jaboticabal, 2013.

SILVA, F.M. et al. Desempenho de um aquecedor de água a biogás. Engenharia Agrícola, v.25, n.3, p.608-614, 2005.

SUZUKI, Ana Beatryz Prenzier et al. Utilização de manipueira juntamente com sólidos da cama de aviário em biodigestores para geração de biogás / Use of cassava wastewater with solid poultry manure in anaerobic digesters to generate biogas. Revista Ambiência, [s.1.], v. 8, n. 3, p.809-819, 30 dez. 2012. GN1 Genesis Network.

http://dx.doi.org/10.5777/ambiencia.2012.0 5.01 .

TESSARO, A. B. et al., Potencial energético da cama de aviário produzida na região sudoeste do Paraná e utilizada como 
Brazilian Journal of Biosystems Engineering v. 11(4): 373-384, 2017

substrato para a produção de biogás. Agronegócio e Meio Ambiente, Maringá, v. 8, n. 2 p.357-377, maio/ago, 2015.

ZEB, Iftikhar et al. Recycling separated liquid-effluent to dilute feedstock in anaerobic digestion of dairy manure. Energy, [s.1.], v. 119, p.1144-1151, jan. $2017 . \quad$ Elsevier BV. http://dx.doi.org/10.1016/j.energy.2016.11. 075 . 